\title{
Effect of air-particle abrasion protocols on the biaxial flexural strength, surface characteristics and phase transformation of zirconia after cyclic loading
}

Özcan, Mutlu ; Melo, Renata M ; Souza, Rodrigo O A ; Machado, João P B ; Felipe Valandro, Luiz ; Botttino, Marco A

\begin{abstract}
This study evaluated the effect of air-particle abrasion protocols on the biaxial flexural strength, surface characteristics and phase transformation of zirconia after cyclic loading. Disc-shaped zirconia specimens (Ø: $15 \mathrm{~mm}$, thickness: $1.2 \mathrm{~mm})(\mathrm{N}=32)$ were submitted to one of the air-particle abrasion protocols ( $\mathrm{n}=8$ per group): (a) $50 \mu \mathrm{m} \mathrm{Al} 2 \mathrm{O} 3$ particles, (b) $110 \mu \mathrm{m} \mathrm{Al} 2 \mathrm{O} 3$ particles coated with silica (Rocatec Plus), (c) $30 \mu \mathrm{m} \mathrm{Al} 2 \mathrm{O} 3$ particles coated with silica (CoJet Sand) for 20s at 2.8bar pressure. Control group received no air-abrasion. All specimens were initially cyclic loaded $(\times 20,000,50 \mathrm{~N}, 1 \mathrm{~Hz})$ in water at $37^{\circ} \mathrm{C}$ and then subjected to biaxial flexural strength testing where the conditioned surface was under tension. Zirconia surfaces were characterized and roughness was measured with 3D surface profilometer. Phase transformation from tetragonal to monoclinic was determined by Raman spectroscopy. The relative amount of transformed monoclinic zirconia (FM) and transformed zone depth (TZD) were measured using XRD. The data (MPa) were analyzed using ANOVA, Tukey's tests and Weibull modulus $(\mathrm{m})$ were calculated for each group $(95 \% \mathrm{CI})$. The biaxial flexural strength $(\mathrm{MPa})$ of CoJet treated group $(1266.3 \pm 158(\mathrm{~A}))$ was not significantly different than that of Rocatec Plus group $(1179 \pm 216.4(\mathrm{~A}, \mathrm{~B}))$ but was significantly higher than the other groups (Control: $942.3 \pm 74.6(\mathrm{C}) ; 50 \mu \mathrm{m}$ Al2O3: $915.2 \pm 185.7(\mathrm{~B}, \mathrm{C})$ ). Weibull modulus was higher for control $(m=13.79)$ than those of other groups $(m=4.95, m=5.64, m=9.13$ for group a, b and c, respectively). Surface roughness $(\mathrm{Ra})$ was the highest with $50 \mu \mathrm{m} \mathrm{Al} 2 \mathrm{O} 3(0.261 \mu \mathrm{m})$ than those of other groups $(0.15$ $0.195 \mu \mathrm{m})$. After all air-abrasion protocols, FM increased (15.02\%-19.25\%) compared to control group (11.12\%). TZD also showed increase after air-abrasion protocols $(0.83-1.07 \mu \mathrm{m})$ compared to control group $(0.59 \mu \mathrm{m})$. Airabrasion protocols increased the roughness and monoclinic phase but in turn abrasion with $30 \mu \mathrm{m} \mathrm{Al} 2 \mathrm{O} 3$ particles coated with silica has increased the biaxial flexural strength of the tested zirconia.
\end{abstract}

DOI: https://doi.org/10.1016/j.jmbbm.2013.01.005

Posted at the Zurich Open Repository and Archive, University of Zurich

ZORA URL: https://doi.org/10.5167/uzh-89934

Journal Article

Accepted Version

Originally published at:

Özcan, Mutlu; Melo, Renata M; Souza, Rodrigo O A; Machado, João P B; Felipe Valandro, Luiz; Botttino, Marco A (2013). Effect of air-particle abrasion protocols on the biaxial flexural strength, surface characteristics and phase transformation of zirconia after cyclic loading. Journal of the Mechanical Behavior of Biomedical Materials, 20:19-28.

DOI: https://doi.org/10.1016/j.jmbbm.2013.01.005 


\section{Effect of air-particle abrasion protocols on the biaxial flexural strength, surface characteristics and phase transformation of zirconia after cyclic loading}

Mutlu Özcan ${ }^{\mathrm{a},{ }^{*}}$, Renata M. Melo ${ }^{\mathrm{b}}$, Rodrigo O.A. Souza ${ }^{\mathrm{c}}$, João P.B. Machado ${ }^{\mathrm{d}}$, Luiz Felipe Valandro ${ }^{\mathrm{e}}$, Marco A. Botttino ${ }^{\text {b }}$

aUniversity of Zürich, Dental Materials Unit, Center for Dental and Oral Medicine, Clinic for Fixed and Removable Prosthodontics and Dental Materials Science, Plattenstrasse 11, CH-8032, Zurich, Switzerland

'São Paulo State University, São José dos Campos Dental School, Department of Dental Materials and Prosthodontics, 777 Eng. Franscisco José Longo Avenue, 12245-000, São José dos Campos, SP, Brazil

${ }^{c}$ Federal University of Paraíba, Department of Restorative Dentistry, Division of Prosthodontics, 9216 Praia de Guajirú Avenue, 59092-220, Natal, RN, Brazil

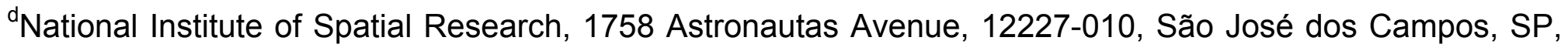
Brazil

${ }^{\mathrm{e}}$ Federal University of Santa Maria, Department of Restorative Dentistry, Division of Prosthodontics, 1184 Marechal Floriano St., 97015-372, Santa Maria, RS, Brazil

*Corresponding author at: Mutlu Özcan, Prof. Dr.med.dent., Ph.D., Dental Materials Unit, University of Zurich, Center for Dental and Oral Medicine, Clinic for Fixed and Removable Prosthodontics and Dental Materials Science, Plattenstrasse 11, CH 8032, Zurich, Switzerland. Tel: +41 44 6343251; fax: +41 446344305.

E-mail address: mutluozcan@hotmail.com 


\section{ABSTRACT}

This study evaluated the effect of air-particle abrasion protocols on the biaxial flexural strength, surface characteristics and phase transformation of zirconia after cyclic loading. Disc-shaped zirconia specimens $(\varnothing$ : $15 \mathrm{~mm}$, thickness: $1.2 \mathrm{~mm})(\mathrm{N}=32)$ were submitted to one of the air-particle abrasion protocols $(\mathrm{n}=8$ per group): a) $50 \mu \mathrm{m} \mathrm{Al} \mathrm{O}_{3}$ particles, b) $110 \mu \mathrm{m} \mathrm{Al} \mathrm{O}_{3}$ particles coated with silica (Rocatec Plus), c) $30 \mu \mathrm{m} \mathrm{Al}_{2} \mathrm{O}_{3}$ particles coated with silica (CoJet Sand) for $20 \mathrm{~s}$ at 2.8 bar pressure. Control group received no air-abrasion. All specimens were initially cyclic loaded $(x 20.000,50 \mathrm{~N}, 1 \mathrm{~Hz})$ in water at $37^{\circ} \mathrm{C}$ and then subjected to biaxial flexural strength testing where the conditioned surface was under tension. Zirconia surfaces were characterized and roughness was measured with 3D surface profilometer. Phase transformation from tetragonal to monoclinic was determined by Raman spectroscopy. The relative amount of transformed monoclinic zirconia $\left(F_{M}\right)$ and transformed zone depth (TZD) were measured using XRD. The data (MPa) were analyzed using ANOVA, Tukey's tests and Weibull modulus $(m)$ were calculated for each group (95\% $\mathrm{Cl})$. The biaxial flexural strength $(\mathrm{MPa})$ of CoJet treated group $\left(1266.3 \pm 158^{\mathrm{A}}\right)$ was not significantly different than that of Rocatec Plus group $\left(1179 \pm 216.4^{\mathrm{A}, \mathrm{B}}\right.$ ) but was significantly higher than the other groups (Control: $\left.942.3 \pm 74.6^{\mathrm{C}} ; 50 \mu \mathrm{m} \mathrm{Al}_{2} \mathrm{O}_{3}: 915.2 \pm 185.7^{\mathrm{B}, \mathrm{C}}\right)$. Weibull modulus was higher for control $(m=13.79)$ than those of other groups ( $m=4.95, m=5.64, m=9.13$ for group $\mathrm{a}, \mathrm{b}$ and $\mathrm{c}$, respectively). Surface roughness $\left(\mathrm{R}_{\mathrm{a}}\right)$ was the highest with $50 \mu \mathrm{m} \mathrm{Al} \mathrm{O}_{3}(0.261 \mu \mathrm{m})$ than those of other groups $(0.15-0.195 \mu \mathrm{m})$. After all air-abrasion protocols, $F_{M}$ increased (15.02-19.25\%) compared to control group (11.12\%). TZD also showed increase after air-abrasion protocols $(0.83-1.07 \mu \mathrm{m})$ compared to control group $(0.59 \mu \mathrm{m})$. Air-abrasion protocols increased the roughness and monoclinic phase but in turn abrasion with $30 \mu \mathrm{m} \mathrm{Al}_{2} \mathrm{O}_{3}$ particles coated with silica has increased the biaxial flexural strength of the tested zirconia.

Keywords: Air-abrasion; Biaxial flexural strength; Silica coating; Y-TZP; Zirconia 


\section{Introduction}

Currently, Yttria-stabilized tetragonal zirconia polycrystal (hereon: zirconia) is the most studied ceramic, mainly due to its high modulus of elasticity (White et al., 2005), wear resistance (Tsukamoto et al., 2008), strength and most importantly, its toughness (Guazzato et al., 2004a). These properties enabled zirconia to be milled through CAD/CAM procedures. Toughness of zirconia is related to capacity of tolerating damage and phase transformation where the tetragonal phase is transformed into the monoclinic phase (Kosmac et al., 1999; Guazzato et al., 2005). During this transformation, the energy absorbed by the zirconia matrix in the vicinity of the propagating crack is consumed by the tetragonal $(t)$ grains to transform into a monoclinic $(m)$ symmetry that is accompanied by $\sim 3-4 \%$ volume expansion. This volume expansion hinders crack propagation by means of compressive stress (Kosmac et al., 1999; Guazzato et al., 2005).

In dentistry, zirconia is used as a framework material for single crowns and fixed dental prosthesis (FDPs). With the awareness in tooth preservation and the advances in adhesive dentistry, zirconia is also indicated for resin-bonded FDPs where the restoration is adhered on the tooth surface with no or minimal preparations. The survival of such resin-bonded FDPs relies on the durable adhesion of the resin cement both to the zirconia and the tooth surface. As such, surface conditioning of ceramics prior to cementation has become a common procedure. Unfortunately, zirconia in particular is an acid-resistant ceramic. Thus, it is not sensitive to topographic changes by acid etching in order to achieve adequate micromechanical retention (Kern and Wegner, 1998; Özcan and Vallittu, 2003; Kern, 2009; Thompson et al., 2011). In order to compensate for this, adhesive cements containing functional monomers, air-abrasion by means of alumina or with silica coated alumina particles, has been suggested to clean the zirconia surface and promote adhesion of the resin cements (Kern, 2009). Silica-modified particle deposition is chemically more reactive to the resin as they require application of silane coupling agents promoting wettability of the resin, the so-called tribochemical silica coating (Guggenberger, 1989). Against its advantages, while increasing the surface roughness of a zirconia (Della Bona et al., 2007), air-particle abrasion may cause flaws and defects on 
zirconia (Zhang et al., 2004, 2005, 2006). Despite the phase transformation and compressive stresses that could prevent crack growth, its strength decreases.

Zirconia is much stronger under monotonic loading than cyclic loading (Morena et al., 1986; Itinoche et al., 2006; Studart et al., 2007a, 2007b). Under monotonic loading, the ceramics simply fail due to surface cone crack growth, whereas cycling loading causes both accumulated plastic damage and phase transformation (Vult von Steyern et al., 2006; Oilo et al., 2009). Moreover, it has been shown that under cycling loading in a wet medium, the crack propagation velocity increases (De Aza et al., 2002; Zhou et al., 2007; Huang et al., 2008). There have been some concerns regarding the application of air-abrasion protocols on the long-term behaviour of zirconia (Kosmac et al., 1999, 2000; Zhang et al., 2004, 2005, 2006).

Abrasives deposited on zirconia surfaces in these studies were of aluminium trioxide $\left(\mathrm{Al}_{2} \mathrm{O}_{3}\right)$ with average particle size ranging between 50 to $250 \mu \mathrm{m}$ in size (Özcan et al., 1998). Alumina particles coated with silica (Rocatec Plus) through the sol gel processes with average particle size up to $110 \mu \mathrm{m}$, have been initially introduced for conditioning metal or ceramic surfaces by the dental technicians at the laboratory. Later, the chairside application of tribochemical coating became possible with the development of $30 \mu \mathrm{m}$ alumina particles coated with silica (CoJet System) (Özcan, 2003). In fact, abrasive particles vary in morphology and it can be anticipated that their impact on the zirconia surface may vary as a function of their morphology and other deposition parameters. Previous studies concentrated mainly on the effect of most commonly used $\mathrm{Al}_{2} \mathrm{O}_{3}$ particles (Kosmac et al., 1999, 2000; Zhang et al., 2004, 2005, 2006) but to the authors` best knowledge, it is not known whether small size silica coated particles with more favorable morphology may result in less transformation into a monoclinic phase or not. Since surface conditioning of cementation surfaces of zirconia FDPs is a common practice in dentistry, the maintenance of mechanical properties of zirconia after these procedures is essential. 
The objectives of this study therefore were to evaluate the effect of air-particle abrasion with different abrasives on the biaxial flexural strength, surface characteristics and phase transformation of a commercial zirconia after cyclic loading in wet conditions. The null hypothesis tested was that air-particle abrasion protocols would neither influence the flexural strength nor the phase transformation of zirconia.

\section{Materials and methods}

\subsection{Specimens preparation}

Brands, types, manufacturers and batch numbers of the tested materials are listed in Table 1.

Disc-shaped zirconia specimens (Vita In-Ceram 2000 YZ Cubes, Vita Zahnfabrik, Bad Säckingen, Germany) ( $: 15 \mathrm{~mm}$, thickness: $1.2 \mathrm{~mm})(\mathrm{N}=32)$ were obtained from the manufacturer, prepared according to ISO 6872,1998 . The final sintering temperature applied was $1500^{\circ} \mathrm{C}$. The specimens were ground finished with $10 \mu \mathrm{m}$ diamond paper on both sides by the manufacturer [Kosmac et al., 1981; Pittayachawan et al., 2007). The thickness and diameter of each specimen were verified by measuring with a digital caliper (Starrett 727, Starrett, Itu, Brazil).

The specimens were air-particle abraded with one of the abrasives ( $\mathrm{n}=8$ per group): a) $50 \mu \mathrm{m} \mathrm{Al}_{2} \mathrm{O}_{3}$ particles (Polidental Ltd, São Paulo, Brasil), b) $110 \mu \mathrm{m} \mathrm{Al} \mathrm{O}_{3}$ particles coated with silica (Rocatec Plus, 3M ESPE, Seefeld, Germany), c) $30 \mu \mathrm{m} \mathrm{Al} \mathrm{O}_{3}$ particles coated with silica (CoJet Sand, 3M ESPE). The specimens that were not air-abraded acted as the control group.

Particles were deposited on the zirconia surfaces using a chairside air-abrasion device (Dento-Prep, RØNVIG A/S, Daugaard, Denmark) adapted to a special metallic holder (Amaral et al., 2008). The nozzle was perpendicular to the specimen surface. The specimens were air-abraded from a distance of $10 \mathrm{~mm}$ for 20 seconds at 2.8 bar pressure. Surface conditioning was performed on the tensile side of the specimen in relation to loading cell during cyclic loading and biaxial flexure strength testing. 


\subsection{Cyclic loading}

All specimens were submitted to mechanical cyclic loading (custom made, Sao Paulo State University, Dental School, Sao Jose dos Campos, Brazil) (Itinoche et al., 2006). The specimens were placed in a metallic base having three balls of $3.2 \mathrm{~mm}$ diameter each, equidistant from each other and forming a plane (ISO 6872, 1998). An upper rod with a $1.6 \mathrm{~mm}$ diameter tip was fixed on the appliance. Cyclic loading was performed under $50 \mathrm{~N}$ for 20.000 times, at a frequency of 1 cycle per second $(1 \mathrm{~Hz})$. The loading was performed in aqueous medium and a thermostat in each chamber kept the temperature constant at $37^{\circ} \mathrm{C}$.

\subsection{Biaxial flexural strength test}

After cyclic loading was completed, the specimens were subjected to monotonic biaxial loading to determine the critical load for fracture. The specimen holder for the experimental set up was the same for both cyclic testing and monotonic loading. The load was applied in a Universal Testing Machine (Emic DL 1000, Emic, São José dos Pinhais, Brazil) at a constant speed of $1 \mathrm{~mm} / \mathrm{mm}$ until fracture occurred.

The biaxial flexural strength (MPa) was calculated using Equations (1-3) according to the guidelines of ISO 6872, 1998:

$$
S=-0.2387 \frac{P(X-Y)}{d^{2}}
$$

(Equation 1)

where $S$ is the maximum tensile stress in Pascals, $P$ is the total load causing fracture in Newtons, and $d$ is the specimen thickness at the origin of the fracture, in millimeters.

$X$ and $Y$ were determined as follows:

$$
X=(1+v) \ln \left(\frac{r_{2}}{r_{3}}\right)^{2}+\left[\left(\frac{1-v}{2}\right)\left(\frac{r_{2}}{r_{3}}\right)^{2}\right]
$$




$$
Y=(1+v)\left[1+\ln \left(\frac{r_{1}}{r_{3}}\right)^{2}\right]+(1-v)\left(\frac{r_{1}}{r_{3}}\right)^{2}
$$

(Equation 3)

where, $v$ is Poisson's ratio (0.25); $r_{1}$ is the radius of the support circle, in $\mathrm{mm}, r_{2}$ is the radius of the loaded area, in $\mathrm{mm} ; r_{3}$ is the radius of the specimen, in $\mathrm{mm} ; d$ is the specimen thickness at the origin of the fracture, in $\mathrm{mm}$.

\subsection{Raman spectroscopy}

Phase transformation $(t \rightarrow m)$ of zirconia after air-particle abrasion, was detected using micro-Raman spectroscopy (RFS 100/S, Bruker Inc, Karlsruhe, Germany) that consists of holographic optics, a single $\sim 1800$ groove/mm grating, $0.5 \mu \mathrm{m}$ spectrometer, and a liquid nitrogen cooled CCD detector (11003330 pixels). The laser (Argon ion, green monochromatic light, $514 \mathrm{~nm}$ ) was focused through a $\times 100$ objective to a $1.5 \mu \mathrm{m}$ beam diameter and two measurements per specimen were carried out, with 4 measurements of 120 seconds each. The peaks related to the monoclinic phase were at 180 and $190 \mathrm{~cm}^{-1}$, whereas the tetragonal polymorphs were represented by all other bands in the collected spectra $\left(148,263,322,466,614,645 \mathrm{~cm}^{-}\right.$ $\left.{ }^{1}\right)$.

\subsection{X-Ray diffraction analysis (XRD)}

The specimens were analyzed in an X-ray Diffractometer (Philips, PW 1830, Almelo, The Netherlands) using monochromatic Cu-K alpha radiation $\left(\lambda=1.54060 \AA\right.$ ). Scans were performed at $40 \mathrm{kV}, 40 \mathrm{~mA}, 0.02^{\circ} / \mathrm{step}$, with step interval ranging from $20^{\circ}$ to $60^{\circ}$, at 1 second per step. 
The relative amount of transformed monoclinic zirconia $\left(F_{M}\right)(\%)$ on the air-abraded surfaces was determined from the integral intensities of the monoclinic (-111)M and (111)M, and the tetragonal (101) $\mathrm{T}$ peaks obtained using XRD, according to the method described by Toraya et al., 1984 using the equations ( $\mathrm{A}$ and $\mathrm{B})$ bellow:

$$
\begin{gathered}
F_{M}=\frac{1.311^{*} X_{M}}{1+0.311^{*} X_{M}} \\
X_{M}=\frac{(-111)_{M}+(111)_{M}}{(-111)_{M}+(111)_{M}+(101)_{T}}
\end{gathered}
$$

Equation $\mathrm{A}$

Equation B

where $(-111) \mathrm{M}, 2 \theta=28^{\circ} ;(111) \mathrm{M}, 2 \theta=31.20 ;(101) \mathrm{T}, 2 \theta=30^{\circ}$, represent the integrated intensity of the peaks diffracted in the monoclinic planes (-111)M and (111)M and in the tetragonal plane (101)T.

Two measurements were carried out on each specimen to obtain the mean values of $F_{M}$. Raman spectroscopy and XRD measurements were performed on the tensile side of the specimens.

\subsection{Transformed zone depth (TZD)}

The transformed zone depth (TZD) $(\mu \mathrm{m})$ on the air-abraded surfaces of zirconia was calculated from the relative amounts of the monoclinic phase, assuming that, within the transformed surface layer, all the tetragonal grains have transformed into the monoclinic symmetry, according the Equation $\mathrm{C}$ bellow (Kosmac et al., 1981):

$$
T Z D=\left(\frac{\operatorname{sen} \theta}{2 \mu}\right)\left[\ln \left(\frac{1}{1-F M}\right)\right]
$$


where, $\theta=15^{\circ}$ is the angle of reflection; $\mu(=0.0642)$ is the absorption coefficient and $F_{M}$ the relative monoclinic fraction obtained from the Raman analysis on the basis of Equations A and B.

\subsection{D optical profilometer and SEM analyses}

In order to determine the effect of abrasives on the topography and roughness (Ra) of the ceramic surfaces, the same specimens submitted to $F_{M}$ and TZD analyses were further analyzed using a 3D optical profilometer (Wyko, Model NT 1100, Veeco, USA). Quantification of the 3D-surface roughness parameters (Ra) was performed using the software (Wyco Vision 32, Veeco) at x20 magnification (301.3 x $229.2 \mu \mathrm{m})$.

The morphologies of the abrasive particles tested were evaluated under Scanning Electron Microscopy (SEM) (Carl Zeiss NTS, Oberkochen, Germany) at x500 magnification.

\subsection{Statistical analysis}

Statistical analysis was performed using Statistix for Windows (Analytical Software Inc., version 8.0, 2003, Tallahase, FL, USA). Kolmogorov-Smirnov test was applied to evaluate the normal distribution of variables and homogenity test (Levene test) was used to verify the homogeneity of variance. The means (MPa) of each group were analysed by one-way analysis of variance (ANOVA) and Tukeys test to determine significant differences between the experimental groups. Weibull analysis was performed using Minitab Version 14 (Minitab, State College, PA, USA) software. The Weibull statistic was applied based on the formulation where the cumulative distribution function was equal to:

$G(x)=1-\exp \left\{-\left(\frac{x-s_{0}}{s}\right)\right\}$

which corresponds for $\mathrm{s}_{0}=0$ to the following density:

$g(x)-\frac{m}{s}\left(\frac{m}{s}\right)^{m-1} \exp \left\{-\left(\frac{x}{s}\right)^{m}\right\}$. 
$P$ values less than 0.05 were considered to be statistically significant in all tests.

\section{Results}

Homogeneity test verified the uniformity of the data and that none of the ANOVA assumptions were violated (Fig. 1)

Abrasive types tested during air-particle abrasion protocols showed a significant impact on the biaxial flexural strength $(\mathrm{MPa})$ of the tested zirconia $(p<0.05)$. Mean biaxial flexural strength of CoJet treated group (1266.3 \pm 158$)$ was not significantly different than that of Rocatec group $(1179 \pm 216.4)(p>0.05)$ but it was significantly higher than the other groups (Control: $\left.942.3 \pm 74.6 ; 50 \mu \mathrm{m} \mathrm{Al}_{2} \mathrm{O}_{3}: 915.2 \pm 185.7\right)(p<0.05)($ Table 2, Fig. 2).

Weibull distribution presented higher shape value for control $(m=13.79)$ than those of other groups ( $m=4.95, m=5.64, m=9.13$ for $50 \mu \mathrm{m} \mathrm{Al}_{2} \mathrm{O}_{3}$, Rocatec Plus and CoJet, respectively) (Table 3, Fig. 3).

Surface roughness $\left(R_{a}\right)$ was the highest with $50 \mu \mathrm{m} \mathrm{Al} \mathrm{O}_{3}(0.261 \mu \mathrm{m})$ than those of other groups $(0.15-$ $0.195 \mu \mathrm{m})$ (Figs. 4a-d, Table 4).

After all air-abrasion protocols, $F_{M}$ increased (15.02-19.25\%) compared to control group (11.12\%). TZD also showed increase after air-abrasion protocols $(0.83-1.07 \mu \mathrm{m})$ compared to control group $(0.59 \mu \mathrm{m})$ (Table 4).

Raman spectroscopy of air-braded surfaces from representative samples revealed traces of monoclinic doublets $\left(180 \mathrm{~cm}^{-1}\right.$ and $\left.190 \mathrm{~cm}^{-1}\right)$ in the CoJet specimen, whereas in the other groups, such bands were less visible (Fig. 5). However, the XRD revealed peaks indicating a monoclinic phase in the specimens for all groups, including the control (Figs. 6a-d).

SEM images (x500) indicated rougher surface of individual $\mathrm{Al}_{2} \mathrm{O}_{3}$ particles compared to silica coated $\mathrm{Al}_{2} \mathrm{O}_{3}$ particles in the case of Rocatec Plus and CoJet (Figs. 7a-c). 


\section{Discussion}

Numerious studies have been published regarding the effects of different surface conditioning protocols to achieve better adhesion to zirconia (Kern, 2009). However, data concerning the strength of zirconia after surface conditioning protocols specifically using abrasives are limited (Kosmac et al., 1999, 2000; Zhang et al., 2004, 2005, 2006). Therefore, this study was undertaken to evaluate the effect of deposition of different particle types on the mechanical properties and structure of zirconia. Since the particle type had a significant effect on the biaxial flexural strength and phase transformation results, the null hypothesis could be rejected.

Flexural strength of ceramics could be tested either with three-point test (Guazzato et al., 2005; Papanagiotou e al., 2006), four-point test (Giordano et al., 1995; Thompson, 2000), or biaxial flexural strength tests (piston-on-three-ball) (Guazzato et al., 2004b; Curtis et al., 2006a; Itinoche et al., 2006; Yilmaz et al., 2007). Among all these methods, fabrication of specimens for three-point flexural test can introduce defects that may not present the standard clinical conditions (Kelly, 1995). Also, the quality of specimens for this type of test is highly dependent on the superficial finish at the edges (Zeng et al., 1996). It was reported to be impossible to remove all flaws in a ceramic during the production of the specimens (Yilmaz et al., 2007). Since fracture begins at the edges, resistance values show great variation. On the contrary, biaxial flexural strength test does not involve edge chippings or fractures because this area is not subjected directly to the load, producing less variation in the values. For these reasons, in this study biaxial flexural strength test was used.

The results of this current study ranging between 915 and $1266 \mathrm{MPa}$ are higher than those reported earlier (Curtis et al., 2006b), where Lava ceramic (1191 - $1267 \mathrm{MPa}$ ) was studied after different protocols of mechanical cycling. In that study, interestingly after aging in water even increased values were found (1308 MPa). Using the same methodology and ceramic material, Pittayachawan et al. (2007) reported lower results $(1086-1164 \mathrm{MPa})$. These results are even less than the values obtained from air-abraded groups in this study. On the other hand, Kosmac et al. (1999) studied different surface conditioning methods using $110 \mu \mathrm{m}$ 
$\mathrm{Al}_{2} \mathrm{O}_{3}$ particles, grinding papers or burs on zirconia and the biaxial flexural strength data ranged from 543 to $1021 \mathrm{MPa}$. Although ISO standard have been followed, even with the same materials variations could be observed. One reason for the differences in biaxial flexural strength values could be attributed to the variations in sintering temperatures of zirconia tested (Hjerppe et al., 2009). In the clinical situations, the presence of dentin under a zirconia FDP and sealing the two materials with a cement layer may yield to more favorable stress distribution than testing an unsupported disc specimen under flexural load according to ISO norms. The results achieved from this current study or others met the requirements of ADA specifications that recommend a minimum flexural strength value of $100 \mathrm{MPa}$. Yet, it is still questionable whether this value of flexural strength is sufficient in clinical practice when these ceramics are employed (Itinoche et al., 2006).

In this study, the specimens were subjected to cyclic loading in water since oral fluids at $37^{\circ} \mathrm{C}$ together with mechanical stresses could aggravate degradation in strength (Kelly, 1995; Huang et al., 2008). Several previous studies reported a significant reduction in the mechanical resistance of ceramics in aqueous environment when compared to testing in dry environment (Kelly, 1995; Pittayachavan et al., 2007). In the case of feldspathic and alumina-based ceramics, this reduction may reach to $30 \%$ (Sherill and O'Brien, 1974). The degradation process in aqueous environment is due to corrosion of the ceramic causing growth of small faults (Morena et al., 1986). This is highly important for estimating clinical failures of ceramic restorations (Chevalier, 2006; Kelly and Denry, 2008; Denry and Kelly, 2008). Cyclic fatigue in water was shown to present a high impact on the lifespan of different zirconia materials yielding to significantly lower results than when mechanical cycling was performed in dry conditions (Studart et al., 2007a; Studart et al., 2007b).

Certainly, depending on the state of the surface, the ageing kinetics will vary since the total amount of transformed zirconia would be higher than that in the surface of the unconstrained material after the same exposure time (Deville et al., 2006). Cyclic loading conditions and protocols vary between studies. In the 
present study, 20.000 cycles were carried out under $50 \mathrm{~N}$ load at a frequency of $1 \mathrm{~Hz}$. In a similar study, alumina and zirconia ceramic discs were submitted to 20.000 cycles, under the same conditions prior to flexural strength testing (Itinoche et al., 2006). Okutan et al. (2006) practiced 1.200 .000 cycles, at $50 \mathrm{~N}$ and 1.3 Hz to evaluate the fracture strength of ceramic crowns. Sundh and Sjogren (2006) submitted FDPs with zirconia copings to mechanical cycling for 100.000 cycles at $50 \mathrm{~N}$ and noticed that the resistance after fracture ranged between 900 and $1900 \mathrm{~N}$ among the groups. Larsson et al. (2007) subjected FDPs to mechanical cycling for 10.000 cycles at $1 \mathrm{~Hz}$ under loads ranging between 30 and $300 \mathrm{~N}$. Since the aim of this study was to evaluate the effect of cyclic loading on zirconia without fracturing the specimens prior to flexural tests, it was decided to perform 20.000 cycles with a $50 \mathrm{~N}$ load.

Zhang et al. (2004) stated that the strengths of air-abraded zirconia specimens show significant reduction in strength after both dynamic and cyclic tests where the specimens presented large starting flaws. In that study, zirconia specimens were air-abraded using $50 \mu \mathrm{m} \mathrm{Al} \mathrm{O}_{3}$. Interestingly, in this study cyclic loading in water was not detrimental for the silica coated specimens. In previous studies, duration of deposition of abrasive particles ranged between 5 to 15 seconds at $0.5-4$ bar pressure, whereas in this study, particles were deposited for 20 seconds. Moreover, in this study, in contrast to other studies where the specimens were air-abraded free-hand in a non-controlled manner, in this study, deposition parameters were better controlled using a specially designed device. Recently, one study group suggested that air-abrasion at 0.5 bar would still result in favourable adhesion compared to higher pressure levels (Attia and Kern, 2011; Yang et al., 2010). In this study, manufacturer's recommendations of 2.8 bar was applied. Such parameters need to be studied more in depth in future studies.

Studying structural changes in zirconia bring additional information regarding to the changes on zirconia after air-abrasion. Especially, the increase in biaxial flexural strength after the application of $30 \mu \mathrm{m}$ CoJet sand can be explained by the formation of a protective layer against the residual compressive stress on zirconia due to the phase transformation $(t \rightarrow m)$ in the air-abraded (Kosmac et al., 1999; Kosmac et al., 
2000; Guazzato et al., 2005). Indeed, Raman spectroscopy revealed traces of the monoclinic doublet (180 $\mathrm{cm}^{-1}$ and $190 \mathrm{~cm}^{-1}$ ), corresponding to the monoclinic phase, in the CoJet particle treated group, whereas in other groups, such bands were less dominant. Similarly, $F_{M}$ ranged between 11.12 to $19.25 \%$ in all groups, being highest for the CoJet group (19.25\%). In previous studies, the effect of this particle type on structural changes of zirconia was not studied but deposition of $110 \mu \mathrm{ml}_{2} \mathrm{O}_{3}$ at 4 bar, resulted in 12.7 to $15.7 \% \mathrm{~F}_{\mathrm{M}}$ (Kosmac et al., 1999; Kosmac et al., 2000) and $110 \mu \mathrm{m} \mathrm{Al}_{2} \mathrm{O}_{3}$ at 5 bar in 9.5\%. Again, in these studies deposition durations were 15 seconds at 4 bar. It has to be noted that the control group also presented monoclinic phase of $11.12 \%$. Most probably, tension associated with cyclic loading yielded to this result (Curtis et al., 2006a). Furthermore, TZD of the experimental groups varied from 0.59 to $1.07 \mu \mathrm{m}$, with the highest values found in the CoJet group $(1.07 \mu \mathrm{m})$. TZD values correspond to the protective layer against residual compressive stresses that is directly linked with an increase in the mechanical resistance of zirconia. The variation in the values among the studies can be explained by the chemical and structural difference, such as concentration, distribution and type of the oxide stabilizer (Sundh and Sjogren, 2006; Sato et al., 2008) and grain size of zirconia materials (Kosmac et al., 1999; Kosmac et al., 2000).

The biaxial flexural strength results should be coupled with Weibull analysis. All particle types presented lower Weibull modulus as opposed to as-sintered group indicating that air-abrasion decreases reliability of the durability of zirconia. Damage from air-abrasion appears to be equivalent to $1 \mathrm{~N}$ indentation pressure (Zhang et al., 2004). Thus, it possibly produces preferential transformation nucleation around scratches, due to elastic/plastic damage from tensile residual stresses (Deville et al., 2006). Deposition of $110 \mu \mathrm{m} \mathrm{Al}_{2} \mathrm{O}_{3}$ for 15 seconds at 4 bar was able to remove a layer of $60 \mu \mathrm{m}$ from a zirconia ceramic (Kosmac et al., 2000). Already during milling procedures, stress produced by diamond burs leave traces in the form of grooves. While these grooves are more regular in shape, the topography after air-abrasion resembles edge-shaped grooves being responsible for strength degradation (Kosmac et al., 2000; Guazzato et al., 2005). According to Weibull analysis results, although reliability of zirconia before air-abrasion was higher than as-sintered 
group, the lower $m$ values could be compensated with the increase in the mechanical strength especially after air-abrasion with alumina particles coated with silica (CoJet-Sand and Rocatec Plus). Merely the morphology of the particles being more favorable for the silica coated ones may be responsible for less damage on zirconia. Available clinical studies on the survival of zirconia FDPs up to 55 months and 4 years where the FDPS were cemented after $50 \mu \mathrm{m} \mathrm{Al}_{2} \underline{\mathrm{O}}_{3}$ particles at $0.25 \mathrm{MPa}$ for approximately 10 seconds air abrasion presented failure rates of 7 to $13 \%$ as a result of technical problems, with no indication of the negative effect of air-abrasion (Wolfart et al. 2009; Sasse et al., 2012). Long-term clinical observations are required to analyze the influence of the air-particle-abrasion protocols on the longevity of zirconia FDPs.

\section{Conclusion}

From this study, the following could be concluded:

1. Deposition of $50 \mu \mathrm{m} \mathrm{Al}_{2} \mathrm{O}_{3}$ for 20 seconds created more roughness, decreased the biaxial flexural strength and Weilbul modulus of the tested ziconia compared to the control group.

2. Deposition of silica coated alumina, with approximately $110 \mu \mathrm{m}$ or $30 \mu \mathrm{m}$ particle size, increased the biaxial flexural strength but decreased the Weilbul modulus being more favorable for the latter.

3. All abrasive types tested increased the monoclinic level and the transformed zone depth in the zirconia compared to control group.

\section{Acknowledgements}

The authors would like to acknowledge Vita Zahnfabrik $\mathrm{GmbH}$, Bad Säckingen, Germany for generous provision of the zirconia material evaluated.

\section{Conflict of interest}

The authors declare that they have no conflict of interest. 


\section{References}

Attia, A., Kern, M., 2011. Effect of cleaning methods after reduced-pressure air abrasion on bonding to zirconia ceramic. J. Adhes. Dent., 13, 561-567.

Chevalier. J., 2006. What future for zirconia as a biomaterial? Biomater. 27, 535-543.

Curtis, A.R., Wright, A.J., Fleming, G.J.P., 2006a. The influence of simulated masticatory loading regimes on the biaxial flexure strength and reliability of a Y-TZP dental ceramic. J. Dent. 34, 317-325.

Curtis, A.R., Wright, A.J., Fleming, G.J.P., 2006b. The influence of surface modification techniques on the performance of a Y-TZP dental ceramic. J. Dent. 34, 195-206.

De Aza, A.H., Chevalier, J., Fantozzi, G., Schehl, M., Torrecillas, R., 2002. Crack growth resistance of alumina, zirconia and zirconia toughened alumina ceramics for joint prostheses. Biomater. 23, 937-945.

Della Bona, A., Donassollo, T.A., Demarco, F.F., Barrett, A.A., Mecholsky, J.J. Jr., 2007. Characterization and surface treatment effects on topography of a glass-infiltrated alumina/zirconia-reinforced ceramic. Dent. Mater. 23, 769-775.

Denry, I., Kelly, J.R., 2008. State of the art of zirconia for dental applications. Dent. Mater. 24, 299-307.

Deville, S., Chevalier, J., Gremillard, L., 2006. Influence of surface finish and residual stresses on the ageing sensitivity of biomedical grade zirconia. Biomater. 27, 2186-2192.

Giordano, R.A., Pelleiter, L., Campbell, S., Pober, R., 1995. Flexural strength of an infused ceramic, glass ceramic, and feldspathic porcelain. J. Prosthet. Dent. 73, 411-418.

Guazzato, M., Proos, K., Quach, L., Swain, M.V., 2004a. Strength, reliability and mode of fracture of bilayered porcelain/zirconia (Y-TZP) dental ceramics. Biomater. 25, 5045-5052.

Guazzato, M., Albakry, M., Ringer, S.P., Swain, M.V., 2004b. Strength, fracture toughness and microstructure of a selection of all-ceramic materials. Part II. Zirconia-based dental ceramic. Dent. Mater. 20, 449-456. 
Guazzato, M., Quach, L., Albakry, M., Swain, M.V., 2005. Influence of surface and heat treatments on the flexural strength of Y-TZP dental ceramic. J. Dent. 33, 9-18.

Guggenberger, R., 1989. Rocatec system--adhesion by tribochemical coating. Dtsch. Zahnarztl. Z. 1989 44, 874-876.

Hjerppe, J., Vallittu, P.K., Fröberg, K., Lassila, L.V., 2009. Effect of sintering time on biaxial strength of zirconium dioxide. Dent. Mater. 25, 166-171.

Huang, M., Thompson, V.P., Rekow, E.D., Soboyejo, W.O., 2008. Modeling of water absorption induced cracks in resin-based composite supported ceramic layer structures. J. Biomed. Mater. Res. B Appl. Biomater. 84, 124-130.

International Organization for Standardization., 1998. Dental ceramic: Amendment 1, ISO 6872. Geneva: ISO.

Itinoche, M.K., Özcan, M., Bottino, M.A., Oyafuso, D., 2006. Effect of mechanical cycling on the flexural strength of densely sintered ceramics. Dent. Mater. 22, 1029-1034.

Kelly, J.R., 1995. Perspectives on strength. Dent. Mater. 11, 103-110.

Kelly, J.R., Denry, I., 2008. Stabilized zirconia as a structural ceramic: an overview. Dent. Mater. 24, 289298.

Kern, M., Wegner, S.M., 1998. Bonding to zirconia ceramic: adhesion methods and their durability. Dent. Mater. 14, 64-71.

Kern, M., 2009. Resin bonding to oxide ceramics for dental restorations. J. Adhes. Sci. Technol. 23, 10971110.

Kosmac, T., Wagner, R., Claussen, N., 1981. Determination of transformation depths in ceramics containing tetragonal $\mathrm{ZrO}_{2}$. J. Am. Ceram. Soc. 64, C72-C73.

Kosmac, T., Oblak, C., Jevnikar, P., Funduk, N., Marion, L., 1999. The effect of surface grinding and sandblasting on flexural strength and reliability of Y-TZP zirconia ceramic. Dent. Mater. 15, 426-433. 
Kosmac, T., Oblak, C., Jevnikar, P., Funduk, N., Marion, L., 2000. Strength and reliability of surface treated Y-TZP dental ceramics. J. Biomed. Mater. Res. 53, 304-313

Larsson, C., Holm, L., Lovgren, N., Kokubo, Y., Vult Von, S., 2007, Fracture strength of four-unit Y-TZP FPD cores designed with varying connector diameter. An in-vitro study. J. Oral Rehabil. 34, 702-709.

Morena, R., Beaudreau, G.M., Lockwood, P.E., Evans, A.L., Fairhurst, C.W., 1986. Fatigue of dental ceramics in a simulated oral environment. J. Dent. Res. 65, 993-997.

Øilo, M., Tvinnereim, H.M., Gjerdet, N.R., 2009. Qualitative and quantitative fracture analyses of highstrength ceramics. Eur. J. Oral Sci. 117, 187-193.

Okutan, M., Heydecke, G., Butz, F., Strub, Jr., 2006. Fracture load and marginal fit of shrinkage-free $\mathrm{ZrSiO}_{4}$ all-ceramic crowns after chewing simulation. J. Oral Rehabil. 33, 827-832.

Özcan, M., Pfeiffer, P., Nergiz, I., 1998. A brief history and current status of metal-and ceramic surfaceconditioning concepts for resin bonding in dentistry. Quintessence Int. 29, 713-724.

Özcan M., 2003. Evaluation of alternative intra-oral repair techniques for fractured ceramic-fused-to-metal restorations. J Oral Rehabil. 30, 194-203.

Özcan, M., Vallittu PK., 2003. Effect of surface conditioning methods on the bond strength of luting cement to ceramics. Dent. Mater. 19, 725-731.

Papanagiotou, H.P., Morgano, S.M., Giordano, R.A., Pober, R., 2006. In vitro evaluation of low-temperature aging effects and finishing procedures on the flexural strength and structural stability of Y-TZP dental ceramics. J. Prosthet. Dent. 96, 154-164.

Piconi, C., Maccauro, G., 1999. Review: zirconia as a ceramic biomaterial. Biomater. 20:1-25.

Pittayachawan, P., McDonald, A., Petrie, A., Knowles, J.C., 2007. The biaxial flexural strength and fatigue property of LavaTM Y-TZP dental ceramic. Dent. Mater. 23, 1018-1029.

Sasse, M., Eschbach, S., Kern, M., 2012. Randomized clinical trial on single retainer all-ceramic resinbonded fixed partial dentures: Influence of the bonding system after up to 55 months. J. Dent. 40, 783-786. 
Sato, H., Yamada, K., Pezzotti, G., Nawa, M., Ban, S., 2008. Mechanical properties of dental zirconia ceramics changed with sandblasting and heat treatment. Dent. Mater. J. 27, 408-414.

Senyilmaz, D.P., Palin, W.M., Shortall, A.C., Burke, F.J., 2007. The effect of surface preparation and luting agent on bond strength to a zirconium-based ceramic. Oper. Dent. 32, 623-630.

Sherrill, C.A., O'Brien, W.J., 1974. Transverse strength of aluminous and feldspathic porcelain. J. Dent. Res. $53,683-690$.

Studart, A.R., Filser, F., Kocher, P., Gauckler, L.J., 2007a. Fatigue of zirconia under cyclic loading in water and its implications for the design of dental bridges. Dent. Mater. 23, 106-114.

Studart, A.R., Filser, F., Kocher, P., Luthy, H., Gauckler, L.J., 2007b. Cyclic fatigue in water of veneerframework composites for all-ceramic dental bridges. Dent. Mater. 23, 177-185.

Sundh, A., Sjogren, G., 2006. Fracture resistance of all-ceramic zirconia bridges with differing phase stabilizers and quality of sintering. Dent. Mater. 22, 778-784.

Thompson, J.Y., Stoner, B.R., Piascik, J.R., Smith, R., 2011. Adhesion/cementation to zirconia and other non-silicate ceramics: where are we now? Dent. Mater. 27, 71-82.

Toraya, H., Yoshimura, M., Somiya, S., 1984. Calibration curve for quantitative analysis of the monoclinictetragonal $\mathrm{ZrO}_{2}$ system by x-ray diffraction. J. Am. Ceram. Soc. 67, C119-C121.

Tsukamoto, R., Williams, P.A., Clarke, I.C., Pezzotti, G., Shoji, H., Akagi, M., Yamamoto, K., 2008. Y-TZP zirconia runs against highly crosslinked UHMWPE tibial inserts: Knee simulator wear and phasetransformation studies. J. Biomed. Mater. Res. Part B: Appl. Biomater. 86, 145-153.

Vult von Steyern, P., Ebbesson, S., Holmgren, J., Haag, P., Nilner, K., 2006. Fracture strength of two oxide ceramic crown systems after cyclic pre-loading and thermocycling. J. Oral Rehabil. 33, 682-689.

White, S.N., Miklus, V.G., McLaren, E.A., Lang, L.A., Caputo, A.A., 2005. Flexural strength of a layered zirconia and porcelain dental all-ceramic system. J. Prosthet. Dent. 94, 125-131. 
Wolfart, S., Harder, S., Eschbach, S., Lehmann, F., Kern, M., 2009. Four-year clinical results of fixed dental prostheses with zirconia substructures (Cercon): end abutments vs. cantilever design. Eur. J. Oral Sci. 117, 741-749.

Yang, B., Barloi, A., Kern, M., 2010. Influence of air-abrasion on zirconia ceramic bonding using an adhesive composite resin. Dent. Mater. 26, 44-50.

Yilmaz, H., Aydin, C., Gul, B.E., 2007. Flexural strength and fracture toughness of dental core ceramics. J. Prosthet. Dent. 98, 120-128.

Zeng, K., Oden, A., Rowcliffe, D., 1996. Flexure tests on dental ceramics. Int. J. Prosthodont. 9, 434-439.

Zhang, Y., Lawn, B., 2005. Fatigue sensitivity of Y-TZP to microscale sharp-contact flaws. J. Biomed. Mater. Res. Part B: Appl. Biomater. 2B, 388-392.

Zhang, Y., Lawn, B.R., Rekow, D., Thompson, V.P., 2004. Effect of sandblasting on the long-term performance of dental ceramics. J. Biomed. Mater. Res. Part B: Appl. Biomater. 71B, 381-386.

Zhang, Y., Lawn, B.R., Malament, K.A., Thompson, V.P., Rekow, D., 2006. Damage accumulation and fatigue life of particle-abraded ceramics. Int. J. Prosthodont. 19, 442-448.

Zhou, J., Mah, J., Shrotriya, P., Mercer, C., Soboyejo, W.O., 2007. Contact damage in an yttria stabilized zirconia: implications. J. Mater. Sci. Mater. Med. 18, 71-78. 


\section{Captions to tables and figures:}

\section{Tables:}

Table 1 Brands, types, manufacturers and batch numbers of the tested materials.

Table 2 The mean \pm standard deviations of biaxial flexure strength values $(\mathrm{MPa})$ for the experimental groups. *The same superscripted letters indicate no significant differences (Tukey's test, $\alpha=0.05$ ).

Table 3 Shape and scale values of Weibull distribution for the biaxial flexural strength for each group (95\% $\mathrm{Cl})$.

Table 4 Mean values for the relative amount of transformed monoclinic zirconia $\left(F_{M}\right)$, transformed zone depth (TZD) and roughness surface $\left(R_{a}\right)$ for the experimental groups.

\section{Figures:}

Fig. 1 Probability plot of residuals (response in $\mathrm{MPa}$ ) indicating normal distribution by plotting against the predicted values.

Fig. 2 Scatter dot plot and bar graphic of means $( \pm S D)$ of biaxial flexural strength (MPa) values according to air-particle abrasion protocol.

Fig. 3 Weibull probability plot for biaxial flexural strength (MPa) of experimental groups $(95 \% \mathrm{Cl})$.

Figs. 4a-d. 3D graphic representation of the zirconia surfaces for a) As-sintered, b) $\mathrm{Al}_{2} \mathrm{O}_{3}$, c) Rocatec Plus and d) CoJet abraded specimens. Note the red intensity for Group b presenting the roughest surface.

Fig. 5 Raman spectra of zirconia specimens. The arrow indicates the presence of monoclinic doublet (180 $\mathrm{cm}^{-1}$ and $\left.190 \mathrm{~cm}^{-1}\right)$, corresponding to the monoclinic phase.

Figs. 6a-d. XRD analyses of as-received and air-abraded zirconia specimens for all experimental groups. (T) Tetragonal zirconia phase; (M) monoclinic phase. 
Figs. 7a-c. Scanning Electron photomicrographs of a) $\mathrm{Al}_{2} \mathrm{O}_{3}$, b) Rocatec Plus and c) CoJet particles at $x 500$ magnification. Note the rough surface of individual $\mathrm{Al}_{2} \mathrm{O}_{3}$ particles compared to silica coated $\mathrm{Al}_{2} \mathrm{O}_{3}$ particles in $\mathrm{b}$ and $\mathrm{c}$. 


\section{Tables:}

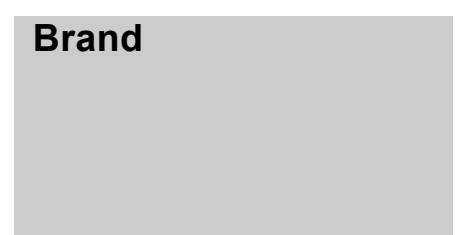

Vita In-Ceram 2000 YZ Y-TZP ceramic Cubes

Rocatec Plus

CoJet-Sand

Aluminium trioxide

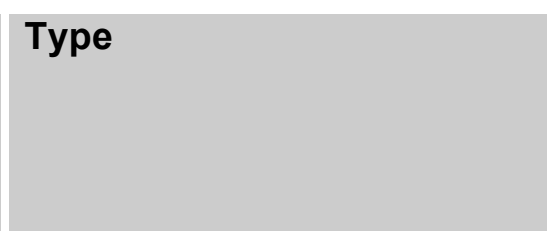

Vita Zahnfabrik, Bad

$110 \mu \mathrm{m}$ alumina particles coated with silica

$30 \mu \mathrm{m}$ alumina particles coated with silica

$50 \mu \mathrm{m}$ alumina particles
Säckingen, Germany

Manufacturer

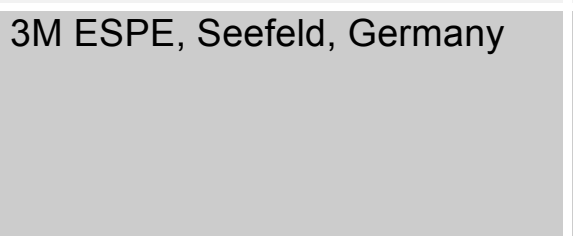

3M ESPE

351794

Batch

number

21970

269078

Polidental Ltd., São Paulo, Brasil

Table 1 Brands, types, manufacturers and batch numbers of the tested materials.

\begin{tabular}{|c|c|c|c|c|}
\hline Experimental groups & Mean \pm SD $(\mathbf{M P a})$ & $\begin{array}{c}\text { Coefficient of } \\
\text { variation (\%) }\end{array}$ & Minimum & Maximum \\
\hline CoJet-Sand & $1266.3 \pm 158^{\mathrm{A}}$ & 12.48 & 521 & 1090.6 \\
\hline Rocatec Plus & $1179 \pm 216.4^{\mathrm{AB}}$ & 18.49 & 777.6 & 1417.1 \\
\hline Aluminium trioxide & $915.2 \pm 185.7^{\mathrm{BC}}$ & 20.30 & 521 & 1090.6 \\
\hline As-sintered & $942.3 \pm 76.5^{\mathrm{C}}$ & 7.92 & 806.2 & 1059.2 \\
\hline
\end{tabular}

Table 2 The mean \pm standard deviations of biaxial flexure strength values $(\mathrm{MPa})$ for the experimental groups. ${ }^{*}$ The same superscripted letters indicate no significant differences (Tukey's test, $\alpha=0.05$ ). 


\begin{tabular}{|c|c|c|c|}
\hline Experimental groups & Shape $(\boldsymbol{m})$ & Scale $(\boldsymbol{s})$ & Correction \\
\hline Aluminium trioxide & 4.95 & 991.14 & 0.881 \\
\hline Rocatec Plus & 5.64 & 1260.79 & 0.973 \\
\hline CoJet-Sand & 9.13 & & 0.834 \\
\hline As-sintered & 13.79 & 1328.69 & 0.981 \\
\hline
\end{tabular}

Table 3 Shape and scale values of Weibull distribution for biaxial flexural strength for each group (95\% Cl).

\begin{tabular}{|c|c|c|c|}
\hline Experimental groups & $\mathrm{F}_{\mathrm{M}}(\%)$ & TZD $(\boldsymbol{\mu m})$ & $\mathbf{R a}(\boldsymbol{\mu m})$ \\
\hline CoJet-Sand & 19.25 & 1.07 & 0.194 \\
\hline Rocatec Plus & 15.02 & 0.83 & 0.195 \\
\hline Aluminium trioxide & 19.08 & 1.06 & 0.261 \\
\hline As-sintered & 11.12 & 0.59 & 0.15 \\
\hline
\end{tabular}

Table 4 Mean values for the relative amount of transformed monoclinic zirconia $\left(F_{M}\right)$, transformed zone depth (TZD) and roughness surface $\left(R_{a}\right)$ for the experimental groups. 
Figures:

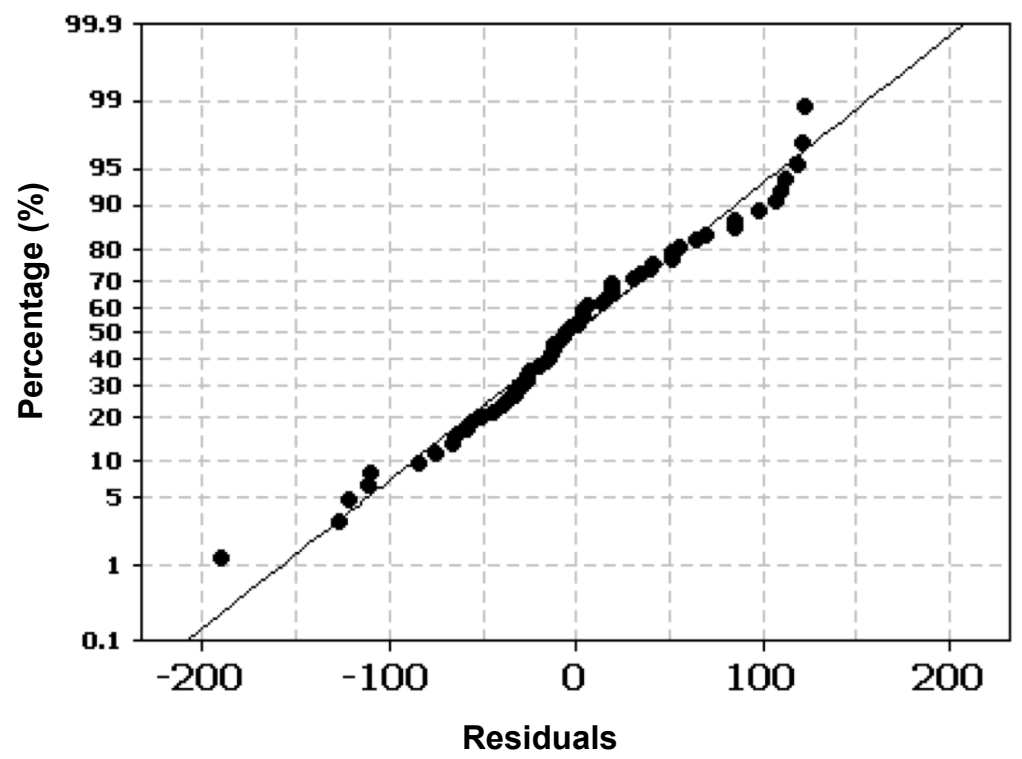

Fig. 1 Probability plot of residuals (response in $\mathrm{MPa}$ ) indicating normal distribution by plotting against the predicted values.

\section{Biaxial Flexural Strength (MPa)}

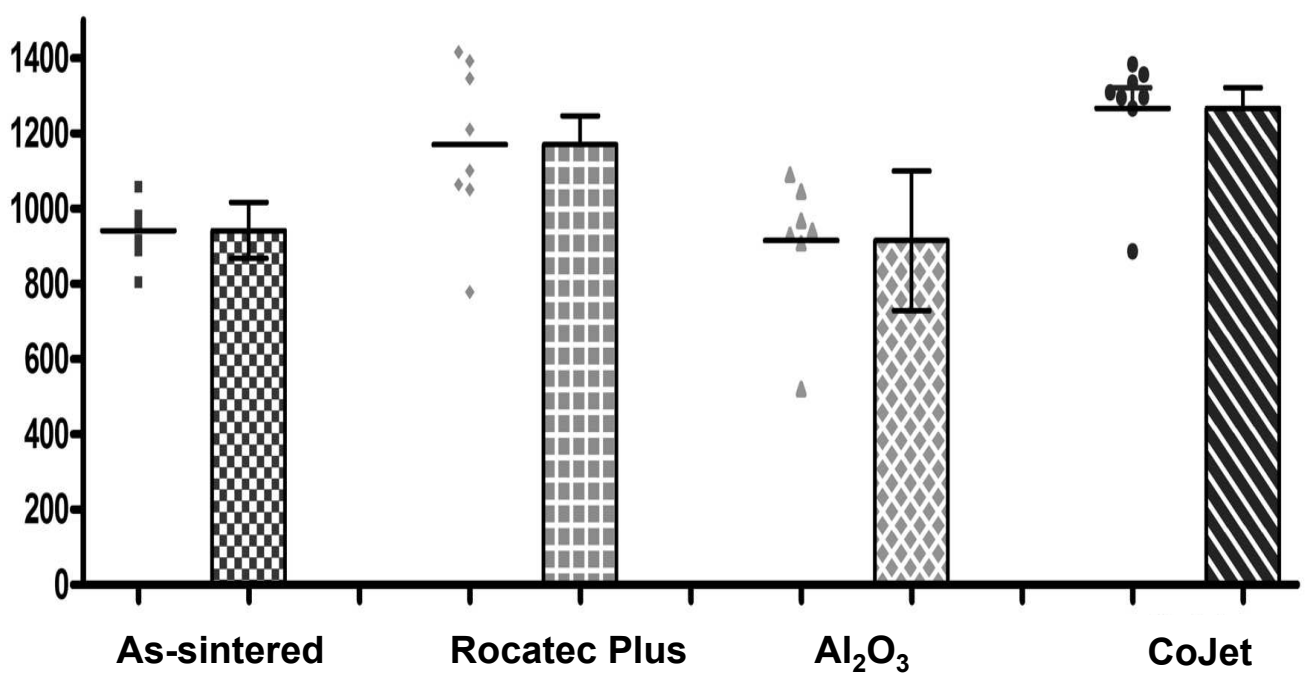

Fig. 2 Scatter dot plot and bar graphic of means ( $\pm S D$ ) of biaxial flexural strength (MPa) values according to airparticle abrasion protocol. 

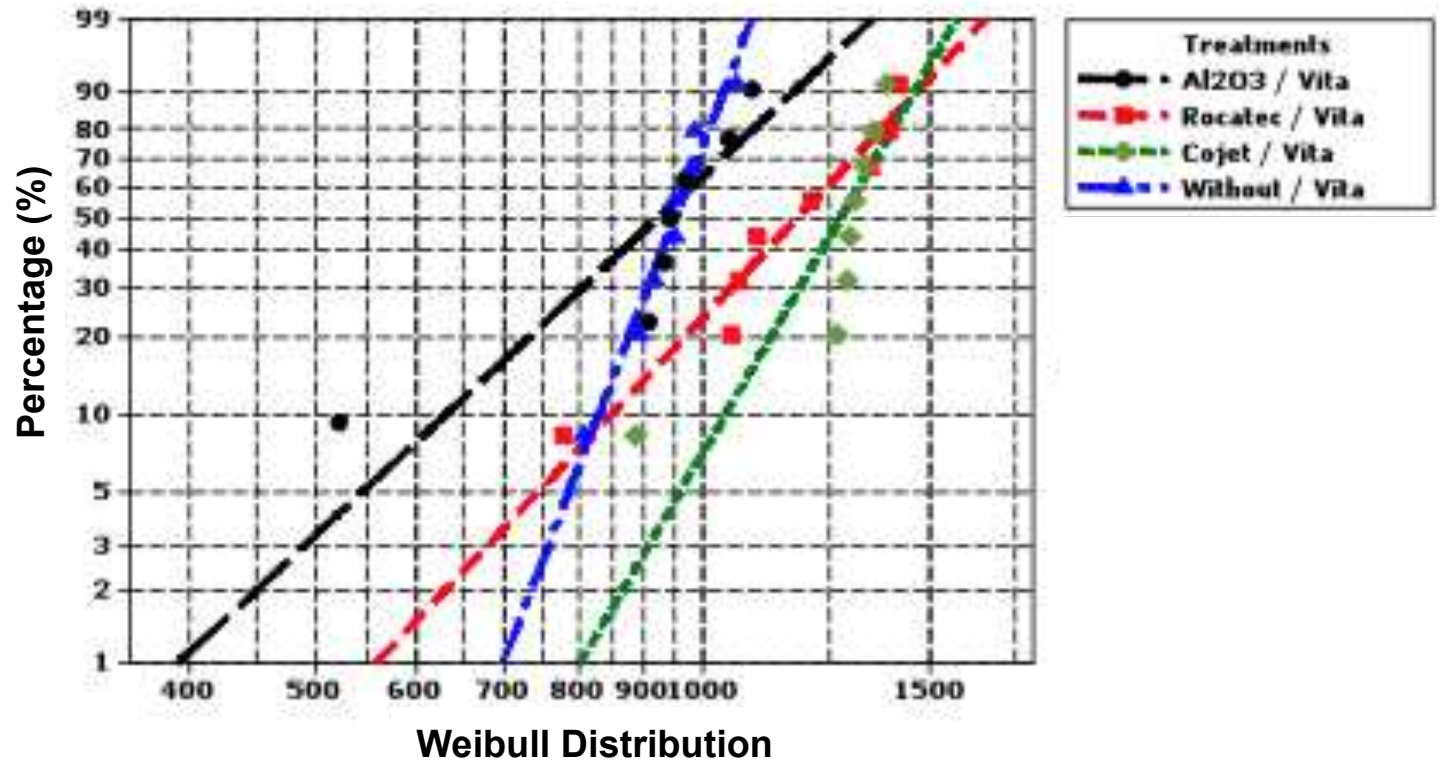

Fig. 3 Weibull probability plot for biaxial flexural strength (MPa) of experimental groups (95\% Cl).

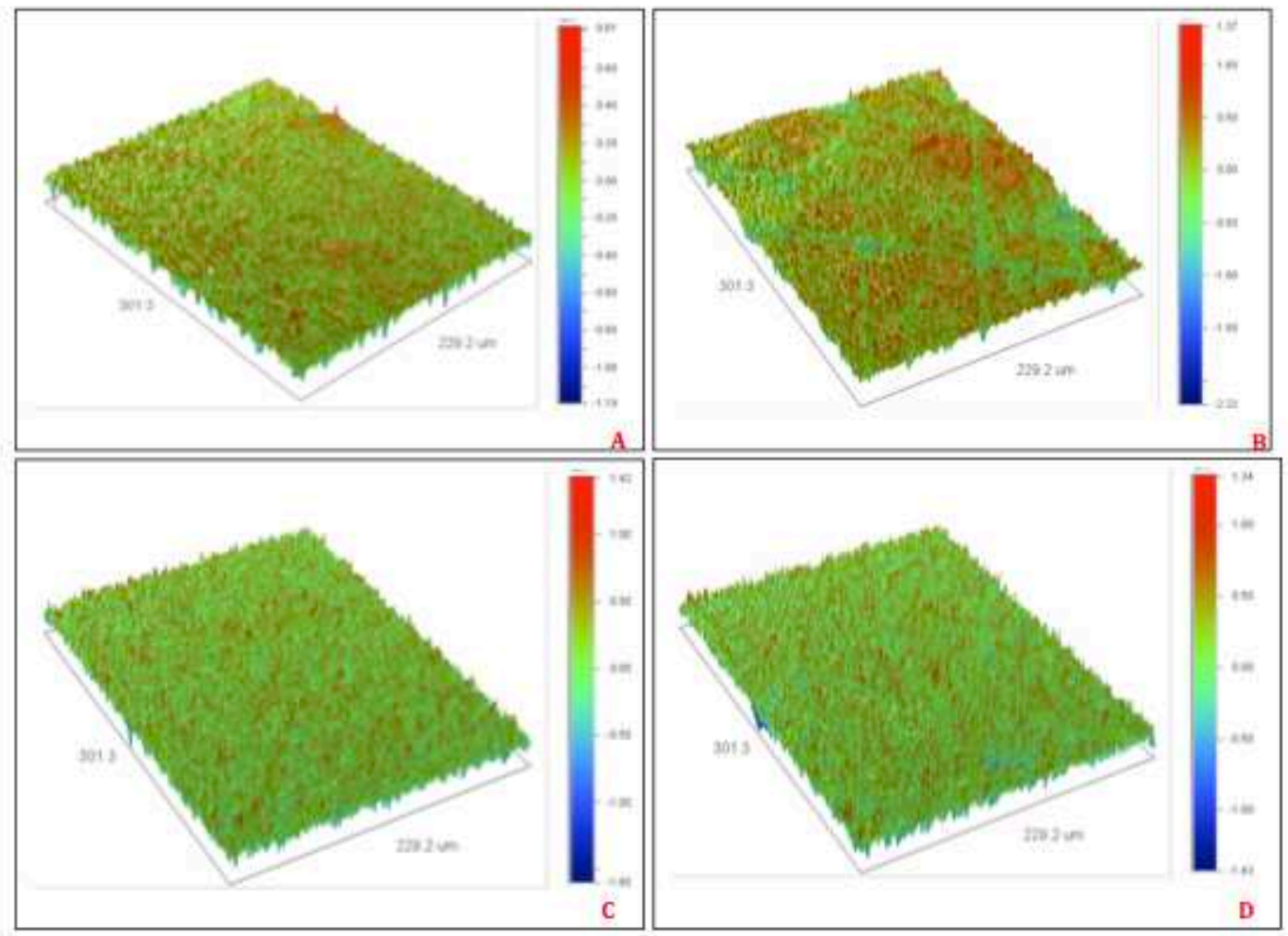

Figs. 4a-d. 3D graphic representation of the zirconia surfaces for a) As-sintered, b) $\mathrm{Al}_{2} \mathrm{O}_{3}$, c) Rocatec Plus and d) 


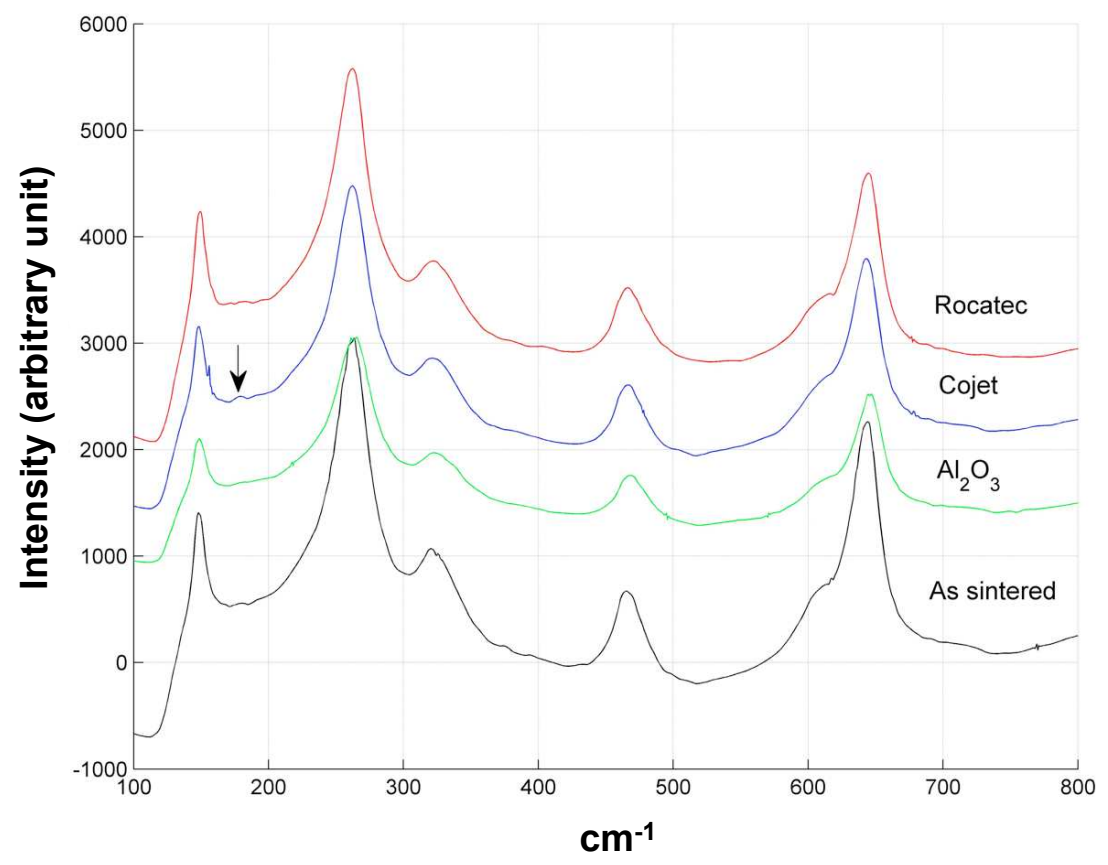

Fig. 5 Raman spectra of zirconia specimens. The arrow indicates the presence of monoclinic doublet $\left(180 \mathrm{~cm}^{-1}\right.$ and $\left.190 \mathrm{~cm}^{-1}\right)$, corresponding to the monoclinic phase. 

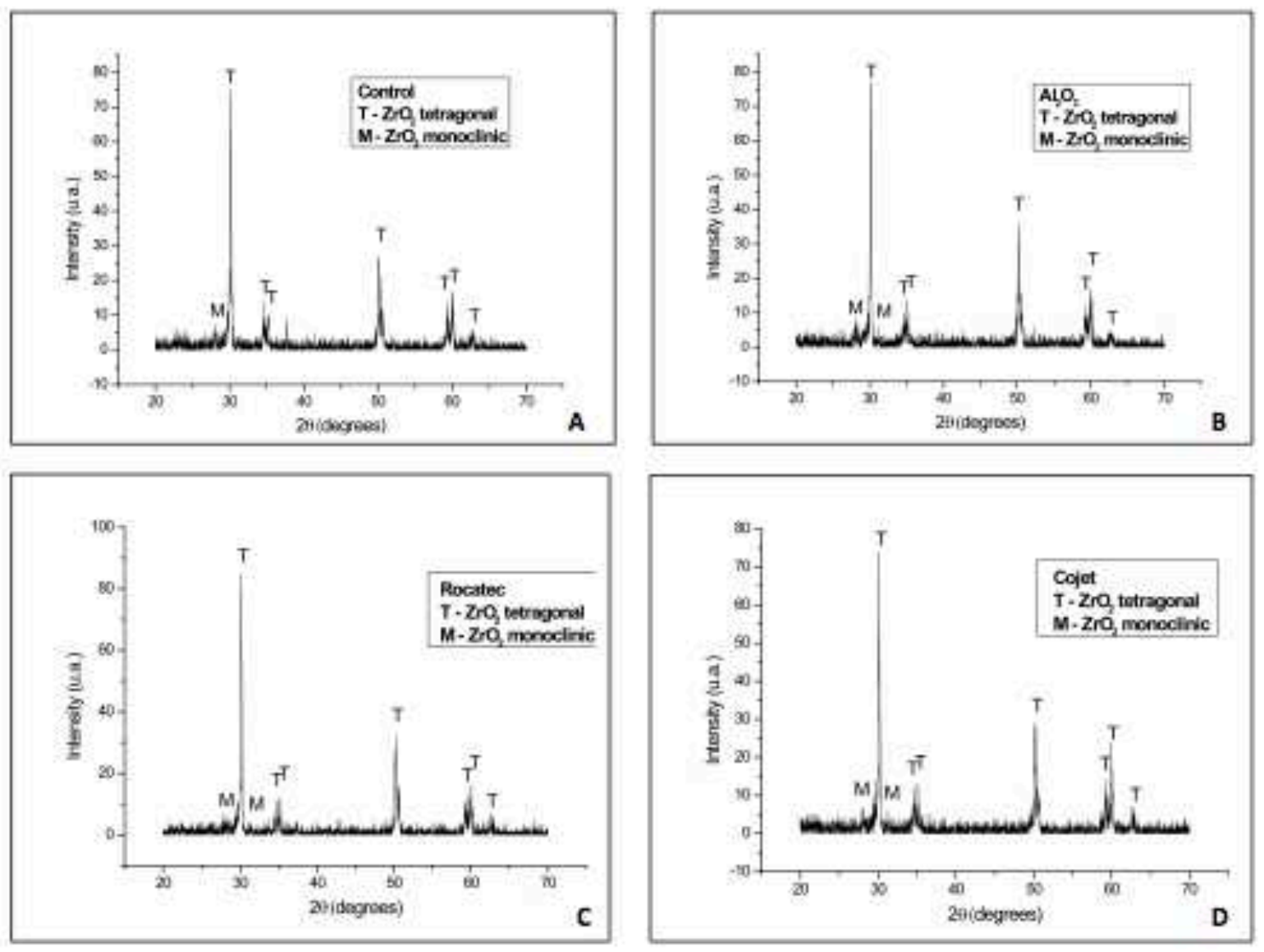

Figs. 6a-d. XRD analyses of as-received and air-abraded zirconia specimens for all experimental groups. (T) Tetragonal zirconia phase; (M) monoclinic phase.
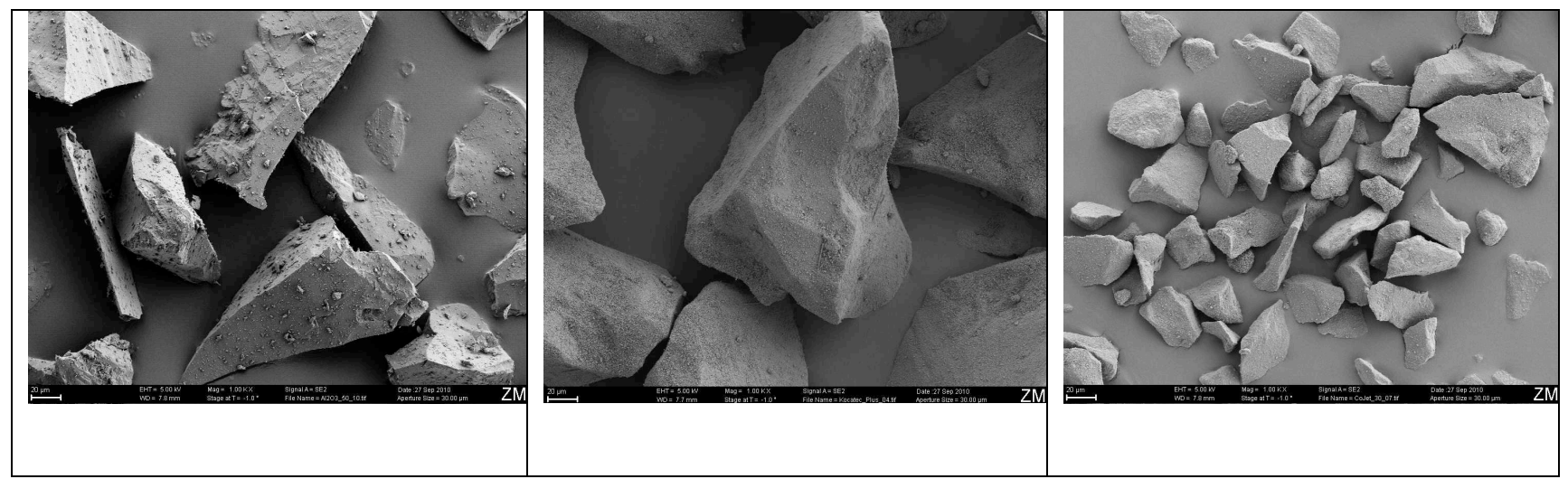

Figs. 7a-c. Scanning Electron photomicrographs of a) $\mathrm{Al}_{2} \mathrm{O}_{3}$, b) Rocatec Plus and c) CoJet particles at $x 500$ magnification. Note the rough surface of individual $\mathrm{Al}_{2} \mathrm{O}_{3}$ particles compared to silica coated $\mathrm{Al}_{2} \mathrm{O}_{3}$ particles in $\mathrm{b}$ and C. 